\title{
Development of Mechanical Engineering in Knowledge Economy: Search for New Business Model
}

\author{
Evgeny Zhernov ${ }^{1 *}$, Evgenia Nekhoda $^{2}$, and Roberto Bruni ${ }^{3}$ \\ ${ }^{1}$ T.F. Gorbachev Kuzbass State Technical University, Department of Economics, 650000 Kemerovo, \\ 28 Vesennyaya St., Russian Federation \\ ${ }^{2}$ National Research Tomsk State University, Department of Strategic Management and Marketing, \\ 634050 Tomsk, 36 Lenin Ave., Russian Federation \\ ${ }^{3}$ University of Cassino and Southern Lazio, Department of Economics and Law, 03043 Cassino, Viale \\ dell’Università, University Campus (Loc. Folcara), Italy
}

\begin{abstract}
The purpose of the study is to propose a procedure for choosing a business model of a machine-building enterprise, depending on the degree of utilization of scientific knowledge of the company's employees in the production. The subject of the article is the search for a new business model based on education and science in order to develop Russian mechanical engineering in the period of the emergence of the knowledge economy. At the same time, mechanical engineering is positioned as a basic branch of the knowledge economy. To select a business model, depending on the degree of use of scientific knowledge at a machinebuilding enterprise, a system of factors and their indicators is substantiated. The identified factors are related to possible knowledge-based business models. When choosing a business model in mechanical engineering, the most adequate to the development of the knowledge economy is the option with a high degree of utilization of scientific knowledge of workers. Therefore, the management of the system of selected factors should be aimed at the predominant use of indicators that provide this option in the production. Knowledge management is selected as the mechanism for implementing the required business model. Prospects for further research are in the organic combination of business modeling with knowledge management technologies created and applied in the dominance of the humanistic paradigm.
\end{abstract}

\section{Introduction}

In the period of the emergence of the knowledge economy the development of Russian mechanical engineering as the driving force of economic growth (the basic branch) requires the search for new business models that would meet the development strategy of the industry as a whole, rather than the survival of its individual enterprises. In this regard, it is useful to refer to the experience of generating new business models in developed foreign countries, most fully presented in $[1,2]$.

*Corresponding author: zhee.eti@kuzstu.ru 
Such an important decision as the choice of a business model, depending on the degree of utilization of scientific knowledge of workers in production, is of particular interest for a modern machine-building enterprise. However, in this aspect, the generation of business models is practically not considered which determines the novelty and relevance of the research issue. In the context of the search for a specified business model, it is important to emphasize that the knowledge management approach in mechanical engineering $[3,4]$ is the development of a process approach that considers enterprise activity as a set of business processes interacting through knowledge sharing that leads to innovations. A business process is a purposeful and time-ordered sequence of operations aimed at bringing a particular business object to the desired state with the specific goals. To obtain a prototype of the future management system, a business model is built, with the help of which the goals and parameters of its project are determined. The business model is always based on the business goals of the company's owners, which fully determine the composition of all its basic components. In the most general form, a business model is a set of graphic and textual descriptions (a set of documents) that allow all interested parties to understand the process of managing an enterprise. In this sense, the business model is a mapping of a real enterprise and its management system. Accordingly, the purpose of forming a business model is to improve the management process when governing body realizes the need to transfer the enterprise to a new stage of production development, product sales, etc.

The purpose of the study is to propose a procedure for choosing a business model of a machine-building enterprise, depending on the degree of utilization of scientific knowledge of the company's employees in the production. The research tasks: 1) to identify the factors influencing the choice of business models with a certain degree of use of scientific knowledge; 2) to correlate the identified factors with possible knowledge-based business models; 3 ) to select the mechanism for implementing the required business model.

\section{Materials and Methods}

Theoretical studies conducted allow us to formulate the following provisions. For business modeling of mechanical engineering companies-manufacturers, the main activity is production. It includes development, manufacture and marketing of the best quality products in the required volume. At the same time, the diversification effect resulting from a larger range of operations and the production of various products is important. For a mechanical engineering enterprise, innovation-oriented business activities are particularly relevant.

Today the intensive process of searching for a business model of mechanical engineering involves seeking ideas from other industries. Moreover, borrowed business models can change the recipient industry: the business model is no longer determined by the industry, but can itself become an agent of change in it. The changes relate primarily to the orientation on efficiency, which must be preceded by a value orientation [5]. Its creation is based on knowledge in the modern economy [6,7].

The "value propositions" of the business model of the mechanical engineering industry include, first of all, such innovative elements as "novelty", "productivity", and "custommade". In the first element, value propositions are oriented towards satisfying completely new needs, which, as a rule, is connected with technological advances. The productivity (efficiency) growth in the second element is more limited by consumer demand than technical capabilities. At the same time, in recent years, the demand for the manufacture of goods for individual orders with the participation of the client itself has increased. The innovative models are essentially about value creation for the company itself, for consumers of its products, and society as a whole 
Due to the need for continuous processing of information at the enterprise, special attention should be paid to the implementation of special analytical systems that perform continuous information search and its research: MIS (Management Information System) [8], OLAP (Online Analytical Processing) [9], and BSC (Balanced Scorecard) [10]. The advantage of these systems is that, based on predetermined criteria, they are able to analyze large arrays of constantly entered information about the business processes being carried out. The biggest obstacle to innovative business models, paradoxically, is not technologies, but people acting under the conditions and rules set by existing public institutions. It causes certain inertia with respect to innovations. The inability of an executive to change thinking from linear to holistic is the main obstacle to innovation in any field of activity. In such a progressive industry as mechanical engineering, the lack of a perspective vision of a new paradigm will not allow the business model to be transformed in time, which inevitably leads to a loss of competitiveness. Knowledge management (hereinafter - KM) can serve as a mechanism for transforming the business model in the knowledge economy. First, the task of KM is to use knowledge to increase productivity by increasing the speed of actions and / or reducing costs, that is, to increase efficiency. The second task, closely related to the first, is innovation: the creation of new products and services, new business processes.

Russian business reality imposes a number of requirements on knowledge management systems: the search for optimal solutions in the field of creating, identifying and sharing knowledge; creating systems aimed at long-term work; the need for systems that can reflect the internal specifics of the business of the enterprise. In order to implement a knowledge management project, an enterprise management formulates the goal and the main content of the project, including a brief definition of a new business concept within the humanistic approach. An example of our shared approach to knowledge management in an organization is the model developed by C.D. Eck [11]. In his opinion, knowledge management becomes the most important factor of creating wealth and provides competitive advantages if in the concept itself it is understood and formed in the aspect of changing paradigms, and is not considered as a structural element of control.

The content of knowledge management at an enterprise is a permanent process of production, distribution and use of knowledge in the course of material production, accompanied by the management of knowledge transfer. This process must necessarily have adequate support within the allocated budget, data banks and organizational design results, taking into account human resources, costs and the beneficial effect of knowledge. Thus, the orientation of enterprises towards the development of a knowledge management strategy in mechanical engineering acts as a search for a more efficient business model based on scientific knowledge and innovations, improvement of production processes, technologies of sales and quality control, corresponding to the new development strategy of the company as a whole.

\section{Results and Discussion}

The choice of a business model depending on the degree of utilization of scientific knowledge at an enterprise is based on the substantiation of a system of factors and their indicators. The factors of choosing a business model for an enterprise are logically divided into internal, comprehensively describing its activities in the period of the formation of the knowledge economy, and external, independent of the enterprise. We attributed to the internal factors 1) technical and production factors (the type of resource intensity of the products manufactured, the technological type of production, the level of innovativeness of the technologies used); 2) cognitive-human factors (the proportion of employees engaged in research and development, in the total number of employees of the enterprise, the level of professional knowledge of employees of the enterprise); 3) management factors (enterprise 
strategy). We attributed the attractiveness of the industry to investors and the uncertainty of the external environment of an enterprise to the external factors (Table).

Table. 1. The procedure for choosing a business model, depending on the degree of utilization of scientific knowledge at a machine-building enterprise.

\begin{tabular}{|c|c|c|c|}
\hline \multirow[t]{2}{*}{ Selection factors } & \multicolumn{3}{|c|}{$\begin{array}{l}\text { Business model with a degree of use of scientific } \\
\text { knowledge }\end{array}$} \\
\hline & low & average & high \\
\hline \multicolumn{4}{|c|}{ 1. Internal factors } \\
\hline \multicolumn{4}{|c|}{ 1.1. Technical and production factors } \\
\hline \multicolumn{4}{|c|}{ 1.1.1. Type of resource intensity of products } \\
\hline 1.1.1.1 science-intensive & & & $\mathrm{X}$ \\
\hline 1.1.1.2 labor-intensive & $\mathrm{X}$ & & \\
\hline 1.1.1.3 material-intensive & $\mathrm{X}$ & & \\
\hline 1.1.1.4 capital-intensive & & $\mathrm{X}$ & \\
\hline 1.1.1.5 energy-intensive & & $\mathrm{X}$ & \\
\hline \multicolumn{4}{|c|}{ 1.1.2. Technological type of production } \\
\hline 1.1.2.1 single & & & $\mathrm{X}$ \\
\hline 1.1.2.2 serial & & $\mathrm{X}$ & \\
\hline 1.1.2.3 mass & $\mathrm{X}$ & & \\
\hline \multicolumn{4}{|c|}{ 1.1.3. The level of innovativeness of technologies applied } \\
\hline 1.1.3.1 innovation-passive enterprise & $\mathrm{X}$ & & \\
\hline 1.1.3.2 innovation-active enterprise & & & $\mathrm{X}$ \\
\hline \multicolumn{4}{|c|}{ 1.2. Cognitive-human factors } \\
\hline \multicolumn{4}{|c|}{$\begin{array}{l}\text { 1.2.1. The proportion of employees engaged in research and development in the total number of } \\
\text { employees }\end{array}$} \\
\hline 1.2.1.1 low & $\mathrm{X}$ & & \\
\hline 1.2.1.2 average & & $\mathrm{X}$ & \\
\hline 1.2.1.3 high & & & $\mathrm{X}$ \\
\hline \multicolumn{4}{|c|}{ 1.2.2. The level of professional knowledge of employees } \\
\hline 1.2.2.1 low & $\mathrm{X}$ & & \\
\hline 1.2.2.2 average & & $\mathrm{X}$ & \\
\hline 1.2.2.3 high & & & $\mathrm{X}$ \\
\hline \multicolumn{4}{|c|}{ 1.3. Management factors } \\
\hline \multicolumn{4}{|c|}{ 1.3.1. Enterprise strategy } \\
\hline 1.3.1 proliferation & & $\mathrm{X}$ & \\
\hline 1.3.2 development & & & $\mathrm{X}$ \\
\hline 1.3 .3 survival & $\mathrm{X}$ & & \\
\hline \multicolumn{4}{|c|}{ 2. External factors } \\
\hline \multicolumn{4}{|c|}{ 2.1. The attractiveness of the industry } \\
\hline 2.1 .1 low & $\mathrm{X}$ & & \\
\hline 2.1 .2 average & & $\mathrm{X}$ & \\
\hline 2.1.3 high & & & $\mathrm{X}$ \\
\hline \multicolumn{4}{|c|}{ 2.2. Uncertainty of the external environment of the enterprise } \\
\hline 2.2 .1 low & $\mathrm{X}$ & & \\
\hline 2.2 .2 average & & $\mathrm{X}$ & \\
\hline 2.2 .3 high & & & $\mathrm{X}$ \\
\hline $\begin{array}{l}\text { Selection of a business model in the } \\
\text { knowledge economy based on the } \\
\text { marginal (cardinal) option - a high degree } \\
\text { of use of scientific knowledge }\end{array}$ & & & $\mathrm{X}$ \\
\hline
\end{tabular}

For modern machine-building production, the characteristic of manufactured products by types of resource intensity as an internal technical-production factor is of paramount 
importance. It is obvious that the production of high technology products will require a business model with a high degree of use of scientific knowledge implemented in innovative technologies. Energy and capital-intensive products are manufactured using appropriate means of production, with the average level of knowledge consumed. Labor and material-intensive products can be produced within a business model with a low degree of use of scientific knowledge.

The second most important internal technical and production factor is the technological type of production. A single type of machine-building production requires universal knowledge from workers with its continuous updating (a high degree of use of scientific knowledge). In the mass type of production, specialization of knowledge stabilizes and reduces its level (low degree of use of scientific knowledge). Serial production is based on the average degree of use of scientific knowledge.

The third internal technical-production factor unites the level of innovativeness of production technologies used in the manufacture of products in terms of innovation-passive and innovation-active enterprise. Innovation-passive enterprises do not implement innovations in the current year and do not plan them in the next three years. Innovationactive enterprises are characterized by a 10 percent increase in innovations both in the current year as compared with the previous year, and in the next three years.

The second group of internal factors - cognitive-human - includes, firstly, the proportion of the company's employees engaged in research and development. Such employees include persons conducting research activities on a systematic basis. Their immediate functions are the increment of new scientific knowledge, the search for applications of this knowledge, the provision of services in the form of research and development. In the period of knowledge economy formation, the share exceeding $50 \%$ can be considered high, medium $-25 \%$ and low - less than $25 \%$. In the first case, cognitiveness is the core of production, focusing primarily on productivity.

It is more difficult to practically determine the second indicator of this group - the level of professional knowledge of employees of the enterprise. Ideally, it should correlate with the level of education received by the employee: high level - higher professional education, average - secondary professional education, low - lack of professional education. Unfortunately, the existing quality of education does not guarantee employers of such a direct relationship.

Among internal management factors, the strategy of an enterprise is of the greatest importance for choosing a business model from the standpoint of scientific knowledge. To determine the strategic goal of the enterprise, it is necessary to develop a target business model. To combine strategy with ethics, it is important to observe the imperative: "Strategy must be moral" [12]. The business model should reflect the ethical obligations of the business to the owners / shareholders, employees, customers, suppliers and society as a whole. Governing body is responsible for the management of the company, not the members of the collective. It is managers who assess and make strategic decisions regarding the prospects of the enterprise. A proliferation strategy corresponds to a business model with an average degree of use of scientific knowledge, a development strategy - with a high one, a survival strategy - with a low one.

External significant factors are 1) the attractiveness of the industry for investors and 2) the uncertainty of the external environment of the enterprise. The low attractiveness of the industry leads to the choice of a business model with a low degree of use of scientific knowledge, the average - with an average, high - with a high. The task of Russian machine builders is to return the industry to its former attractiveness for investors, including through the revival of industry science. The presence of a sectoral business model can play an appropriate role, especially if it is the quintessence of world management experience in the industry. 
The uncertainty of the external macro- and microenvironment of a machine-building enterprise is primarily due to the market, including the global one. To reduce it, senior executives compare their enterprises with enterprises not only of their industry, but also with enterprises of other industries that have managed to adapt to environmental variability. The high uncertainty of the external environment, due to the high rates and frequency of changes, requires the selection of a business model with a high degree of use of scientific knowledge due to the objective need for their rapid updating, the average - with average and low - with low respectively.

In the strategic choice of mechanical engineering business model using scientific knowledge, the most adequate to the knowledge economy formation is a cardinal option with a high degree of utilization of scientific knowledge. Therefore, the management of the system of selected factors should be aimed at the predominant use of indicators that provide this option in the production.

The mechanism for implementing the required business model involves the use of such innovative management technology as knowledge management. This concept in relation to a manufacturing company includes not only the management of employee qualifications, but also the management of the product line, as well as the management of the composition of technologies.

Managing employee qualifications as the leading element of KM is the organization of a system of training in corporate and academic universities of personnel capable of ensuring the functioning of the system for selecting and implementing new business ideas. This function is the prerogative of HR service. The management of the product line under market conditions consists in the organization of the joint effective work of research, design, technology, production and marketing departments of the enterprise.

The basis of the creation of new products and the demand for them is the knowledge of the staff of these departments. For best results, these functions should be centralized at the highest level of enterprise management. Managing the composition of technologies involves monitoring new promising technologies, their selection in accordance with the selected criteria for the optimal structure of the "technology portfolio". Such functions are performed by technical and technological services of the enterprise.

The machine-building enterprises that have established the KM process in close connection with business modeling have thereby secured access to the new technoeconomic paradigm, which allows them to achieve a qualitatively new level of economic efficiency.

Knowledge management understood in this way is considered as a method of searching for a new business model that allows increasing multiply the efficiency of an enterprise in the Russian economy. A business model built with the use of KM technology has the following features:

1) a company must have its own systems for generating new business ideas, developing production and sales technologies, and quality control;

2) knowledge management for maintenance, repair and service of manufacturing system[13];

3) possession of assets that form a complete technological set is not mandatory in the knowledge economy - non-key activities are outsourced;

4) management of the production business system consists in dispatching the placement of orders, including with third-party contractors, as well as in improving the system of movement of material flows (real-time control [14]).

The goal of an effective KM is to develop and implement a strategy for its implementation, ensuring maximum increase in the value of the company. The sequence of implementing knowledge management and the content of the stages may be as follows. 
1. The establishment of the link between the growth of company value and the specific knowledge of its employees - the main value factor which is directly related to cost reduction, revenue and profit growth. Identification of key business processes for the implementation of the adopted strategy and the formulation of requirements for the knowledge of the company's employees which is necessary to carry out these business processes. (We are talking about the definition of so-called "key" knowledge - knowledge that is critical for the company's business success). Developing a base for measuring and assessing the knowledge of employees of the enterprise by their contribution to business success.

2. Description of key business processes to obtain the so-called "procedural" knowledge of employees. A visual representation of the employee actions, during which the strategy is implemented and the value of the company is created.

3. Knowledge audit in the form of defining "knowledge map"[15] of key knowledge, which identifies the places of use and application of knowledge at all stages of business processes, as well as sources of production and knowledge carriers. Determination of the method and place of application of key knowledge, the type of knowledge (explicit or tacit), as well as sources of knowledge; identification of the body of required knowledge, its distribution by enterprise units.

4. Analysis of knowledge maps and assessment of discrepancies between the body of key knowledge needed to increase the value and implement the strategy, and the existing knowledge of the company's employees. Developing KM policy that highlights key knowledge of an enterprise's employees, determines the role of fundamental, innovative knowledge in competition, establishes knowledge to be stored - knowledge the stock of which within the enterprise is sufficient to implement the strategy, and knowledge that needs to be increased due to the above discrepancy. Knowledge policy indicates the approach to the formalization and dissemination of key knowledge.

5. Development of KM strategy based on policy. Determining ways of KM development in three areas: technology, culture and knowledge processes, as well as the distribution of efforts of workers between these areas.

The procedure for selecting a business model of a machine-building enterprise, depending on the degree of utilization of scientific knowledge of employees of the enterprise in the production, is proposed as follows: 1) expert evaluation of the state of the factor of choice existing at the enterprise (marked with an " $X$ " in the table); 2) experts estimate the marginal option for each group of business models; 3) senior management select the business model based on the cardinal option. The procedures are supported by a set of elements of knowledge management technology.

\section{Conclusion}

When choosing a business model with the use of scientific knowledge in mechanical engineering, the most adequate to the knowledge economy formation is the cardinal option with a high degree of utilization of scientific knowledge. Therefore, the management of the system of selected factors should be aimed at the predominant use of indicators that provide this option in the production. Prospects for further research are in the organic combination of business modeling with knowledge management technologies created and applied in the humanistic paradigm.

Different changes are affecting the societies, the economies of the world and the traditional way to stimulate and manage relationships between actors in value creation are changing fast. Companies are searching for new business models able to involve actors to participate in evolving business activities, are searching for more loyal customers and 
partners but the difficulties remain and a solution is of course the knowledge improvement from each side of value proposition and market approach.

The knowledge and technology improvement and diffusion stimulate the emerging benefits per each part involved because the openness can increase the opportunity to find new development ideas and new solutions for worldwide problems in terms of general and diffused customer requests, business competition and environmental needs.

Companies need to change the approach with markets and communities because the sources of new ideas, projects, companies reorganizations, investments, functions and opportunities are identifying new determinants and codes in defining the value. A lot of actors are involved in business development and the value is not only generated by one side. The knowledge diffusion permits to consider the role of relationships network at the base of value co-creation and the knowledge is at the base of actors' involvement. Actors with right knowledge have the opportunity to interact and cooperate and that causes the paradigm useful to understand the evolving of economies and societies. Knowledge emerges as the most relevant immaterial resource able to activate the actors' cooperation and the resource integration toward the value co-creation. Value is co-created by each actor involved in the process of business and market development and the relation between companies and customers represent the pillars of the business and economic system evolution.

New business models need to favor frameworks able to highlight the passage from hierarchical organizations and responsibilities in business development (top down) to a much more smooth resource integration where the relevance of the ideas and projects comes from the effective possibility to share information and co-create opportunities and new value propositions. In that way each actor with right knowledge - employee, manager, director, supplier and customer - could be the stimulator, animator, influencer, activator of new projects involving other actors integrated in the project to be part of the same system in evolution. For this reason, knowledge can implicate the engagement of different actors in the same value proposition. Increasing the knowledge of actors it is possible to increase the opportunity of cooperation getting new ideas and alternative ways to do same things in different ways. Each actor could be stimulated to participate in resource integration, sharing the common goal of the company but, at the same time, the actor should show the will to cooperate in specific activities that, sometime, are far from the immediate return or revenue; that comes from the culture, tradition, knowledge and engagement of the subject for the company or the product / service offering. At the end of the involvement through the knowledge diffusion and sharing the final goal of the integrated system of actors is the survival of the integrated system and the multiplication of opportunities per each actor involved.

\section{Acknowledgements}

The research is done under the financial support of the Russian Foundation for Basic Research, Research Project № 18-010-00340 "Business Models of Companies as the Basis for the Formation of Common Values and Social Capital".

\section{References}

1. A. Osterwalder, Y. Pigneur, Business model generation: a handbook for visionaries, game changers, and challengers (Wiley, Hoboken, New Jersey, 2010)

2. M. Voigt, M. Fordey, A. Malsbender, K. Ortbach, R. Plattfaut, B. Niehaves, Proceedings of the 24th Australasian Conference on Information Systems (2013) 
3. D. Ghelase, L. Daschievici, A. Epureanu, Proceedings of the World Congress on Engineering (WCE 2011), 1, 611 (2011)

4. T. Mezher, M.A. Abdul-Malak, I. Ghosn, M. Ajam, J. Manag. Eng., 21:3, 138 (2005)

5. M.E. Porter, M.R. Kramer, HBR, 1:2, 62 (2011)

6. K. North, G. Kumta, Knowledge management: value creation through organizational learning (Springer, Cham, 2014)

7. K. North, R. Maier, O. Haas, Knowledge management in digital change: new findings and practical cases (Springer, Cham, 2018)

8. R. McLeod jr., Management information systems (Science Research Associates, Chicago, 1979)

9. E.F. Codd, S.B. Codd, C.T. Salley, Providing OLAP (On-line analytical processing) to user-analysts: an IT mandate (Codd \& Associates, Ann Arbor, 1993)

10. R.S. Kaplan, D.P. Norton, The balanced scorecard: translating strategy into action (Harvard Business Review Press, Boston, 1996)

11. C.D. Eck, Die Unternehmung, 51:3, 155 (1997)

12. A. A. Thompson jr., A. J. Strickland III, Crafting and implementing strategy: what every manager should know (Irwin, Burr Ridge, 1995)

13. S. Wan, J. Gao, D. Li, R. Evans, Proceedings of the 12th International Conference on Manufacturing Research (ICMR2014), 65 (2014)

14. F.J. Lerch, D.E. Harter, Inf. Syst. Res., 12:1, 63 (2001)

15. S. Kim, E. Suh, H. Hwang, J. Knowl. Manag., 7:2, 34 (2003) 